\title{
Parámetros para la planificación estratégica del turismo en la parroquia de Tumbaco, cantón Quito
}

\section{Parameters for strategic tourism planning at parish of Tumbaco, Quito}

\author{
Marco Sarango ${ }^{1}$, Enrique Cabanilla ${ }^{1}$ \\ ${ }^{1}$ Universidad Central del Ecuador. Facultad de Ciencias Agricolas. Carrera de Turismo Ecológico. \\ Jerónimo Leiton y Av. La Gasca s/n. Ciudadela Universitaria. Quito. 170521. Ecuador
}

\begin{abstract}
Resumen
El presente artículo presenta información de los elementos turísticos de la parroquia de Tumbaco. Posteriormente, con los datos sistematizados, se realizó un análisis FODA del sistema turístico dentro del territorio. Junto a los estudios anteriores se efectuó una encuesta a los pobladores locales, en dicha encuesta se consultó sobre la aceptación del turismo en esta parroquia. La comunidad expresó su acuerdo y confía en que el turismo sea un medio de desarrollo sostenible. Todo este proceso desemboca en una serie de recomendaciones, producto de la evaluación del diagnóstico y la encuesta, que serán el pilar de un plan estratégico a futuro.
\end{abstract}

Palabras clave: Tumbaco, diagnóstico turístico, turismo, Ecuador.

\begin{abstract}
This article presents information of tourist elements of the parish of Tumbaco. Later, with the systematic data, a SWOT analysis of the tourism system in the territory was conducted. Along with previous studies, a survey was conducted to local people in the survey were asked about to acceptance of tourism in this parish. The community expressed its acceptance and hopes that tourism is a sustainable development tool. This whole process leads to a series of recommendations, product assessment and diagnosis survey, which will be the cornerstone of a future strategic plan.
\end{abstract}

Keywords: Tumbaco, Tumbaco's tourism diagnosis, tourism development, Ecuador.

\section{Introducción}

El cantón Quito y su distrito se encuentran ubicados principalmente sobre la llamada Meseta de Quito, en las faldas orientales del volcán Pichincha, en la Cordillera Occidental de los Andes septentrio- nales de Ecuador. La altura promedio es de 2.850 msnm. La parroquia de Tumbaco, lugar donde se realizó esta investigación, se encuentra en el valle nororiental del cantón Quito, parte de la provincia de Pichincha (Mapa 1). La superficie aproximada de la parroquia es de $182 \mathrm{~km}^{2}$ (GAD Tumbaco, 2012). 


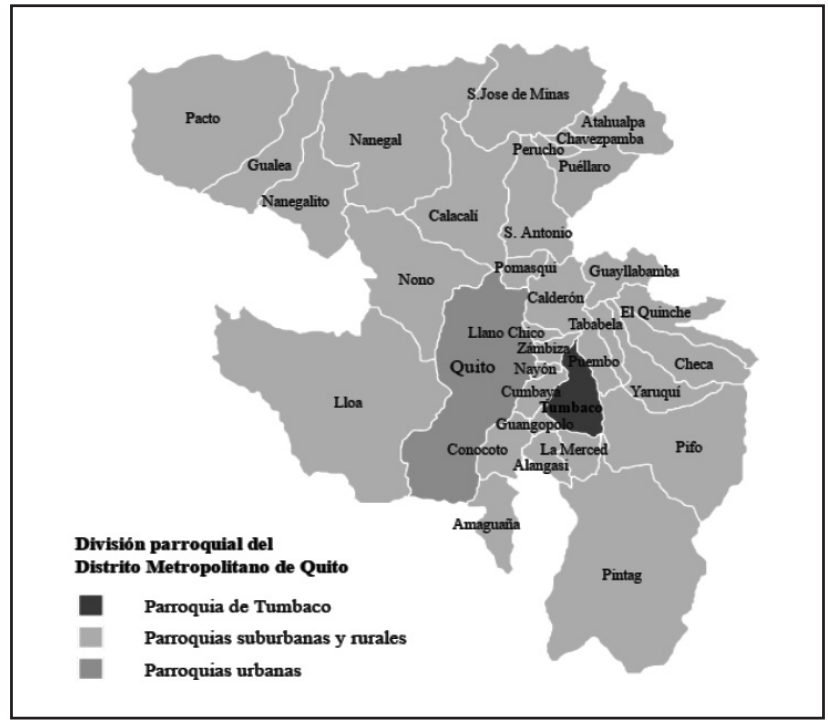

Mapa 1. División territorial del cantón Quito (Wikimedia, 2015).

La distancia desde el distrito de Quito es de 14 $\mathrm{km}$, cuenta con una excelente red vial como muestra la Figura 1. Esta proximidad ha sido aprovechada para implementar varios proyectos inmobiliarios que han servido para descongestionar la trama urbana del distrito metropolitano.

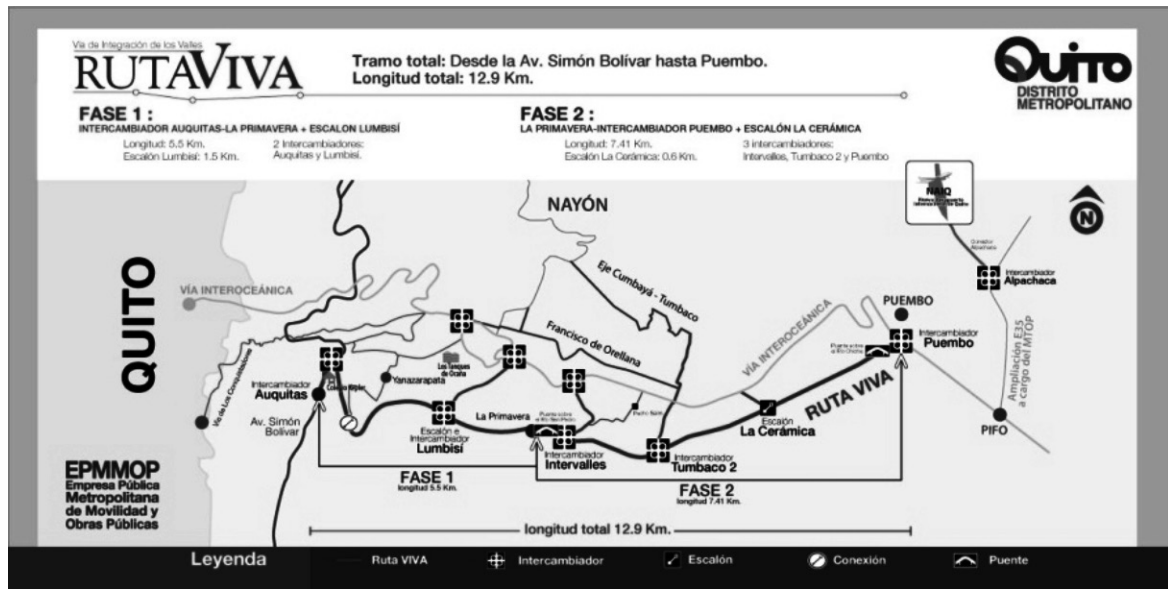

Figura 1. Accesos viales desde Quito hacía la parroquia de Tumbaco. Fuente: Empresa Pública Metropolitana de Movilidad y Obras Públicas (2016).

Pese a la cercanía a Quito Metropolitano, este territorio no presenta la información necesaria para la toma de decisiones en el ámbito turístico, por lo que el presente estudio se enfocará en un diagnóstico de los elementos del sistema turístico, para definir algunas líneas sobre las cuales se podrá plantear, a futuro, un plan estratégico turístico de la parroquia.

En el proceso de investigación se analizaron documentos, de carácter público, elaborados por el Gobierno Autónomo Descentralizado de la Parro- quia de Tumbaco, que junto al Código Orgánico de Organización Territorial de Autonomía y Descentralización, marcan un parámetro sobre el cual el turismo deberá alinearse al vigente Plan de Desarrollo y Ordenamiento Territorial (PDOT) de Tumbaco. Estos suplen, en algo, la ausencia de estudios específicos que recopilen los elementos del sistema turístico de la parroquia.

Con estos antecedentes se realizó una profunda investigación de los elementos del sistema turístico, me- 
diante un minucioso análisis de sus componentes $(\mathrm{Ca}-$ banilla, 2013), se estudiaron los siguientes elementos:

a) La oferta turística donde se integran los componentes: natural, hechos culturales, gastronomía, festividades y eventos, actividades recreacionales, vías de acceso, servicios básicos y servicios turísticos; b) La demanda turística, identificada mediante el componente consumidor y demanda;

c) La comercialización, enmarcada en el componente promoción y comercialización; y,

d) La superestructura donde se aglutinan los componentes de políticas administrativas e instituciones administrativas (Figura 2).

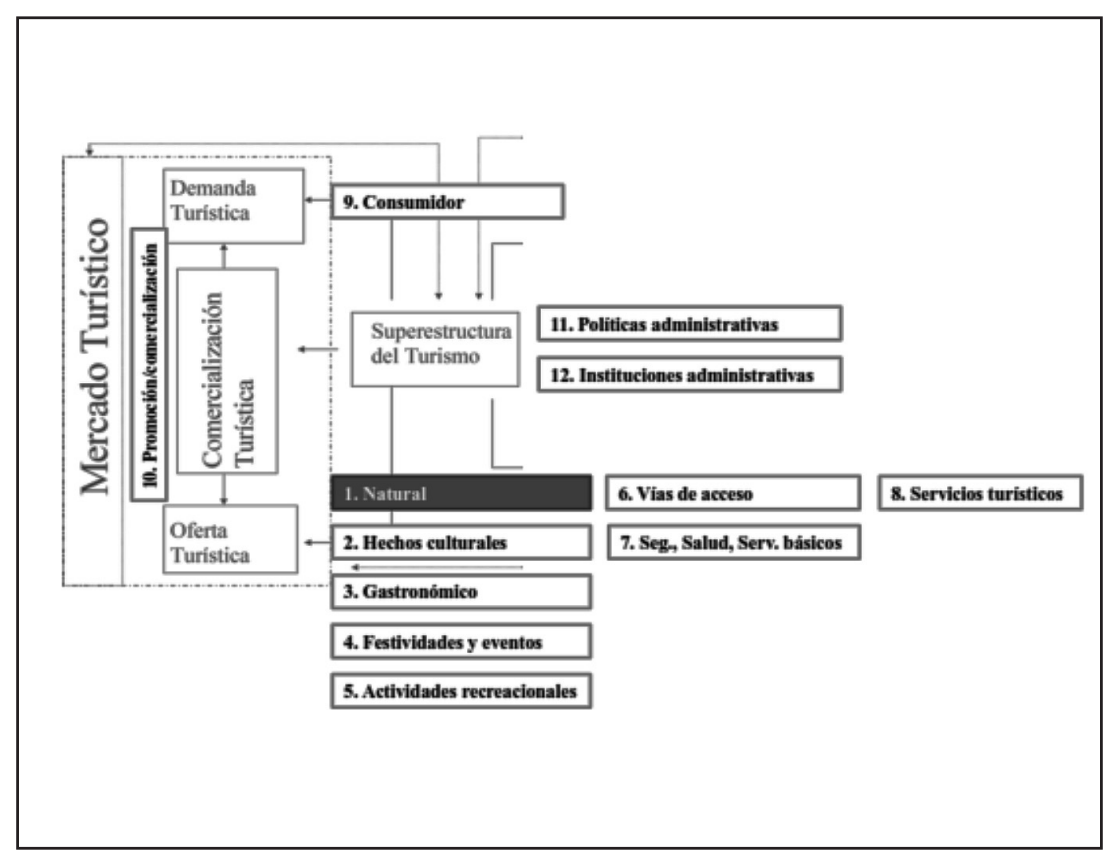

Figura 2. Estructura base para el levantamiento de los elementos del sistema turístico (Cabanilla, 2013).

\section{Materiales y métodos}

El diseño de la investigación es descriptivo, pues se ocupó de la representación de datos y características turísticas de la parroquia de Tumbaco. Su objetivo fue la adquisición de datos precisos y sistemáticos que se utilizaron para elaborar el diagnóstico. Se plantea como un caso de estudio donde se focaliza territorialmente a la parroquia de Tumbaco en una situación real. Describe el contacto del investigador con la realidad natural, cultural y económica del lugar estudiado. Es un informe concreto, fácil de analizar y reflexiona sobre sus hallazgos para elaborar el diagnóstico y sugerir lineamientos para el futuro plan de desarrollo turístico del lugar estudiado.

El método utilizado es mixto, que se define como la integración sistemática de los métodos cuantitativo y cualitativo en un solo estudio, utilizado en este caso para configurar, lo más detalladamente posible, el sistema turístico de la parroquia estudiada. Para llevar a cabo el presente estudio se utilizaron fichas de campo, bitácoras y cuestionarios (entrevistas y encuestas) para el trabajo con los informantes calificados.

\section{Resultados}

\subsection{Sistematización del levantamiento de los ele- mentos del sistema turístico de Tumbaco}

A continuación, en la Tabla 1 se muestra la información obtenida en el trabajo de campo, evaluada desde su posible utilización en el turismo. 
Tabla 1. Elementos del sistema turístico de la parroquia de Tumbaco

\begin{tabular}{|c|c|c|}
\hline Entorno & Elementos sistematizados & Características identificadas relacionadas al turismo \\
\hline \multirow{4}{*}{$\begin{array}{l}\text { Componente } \\
\text { Natural }\end{array}$} & Volcán Ilaló & $\begin{array}{l}\text { Esta elevación de } 3.168 \mathrm{msnm} \text {, es utilizada para senderismo y para as- } \\
\text { censiones de baja intensidad. Su mirador es estratégico ya que se divisan } \\
\text { los valles de Tumbaco y de Los Chillos. }\end{array}$ \\
\hline & $\begin{array}{l}\text { Río San Pedro } \\
\text { Río Alcantarilla } \\
\text { Quebrada de Viñán } \\
\text { Río Chiche }\end{array}$ & $\begin{array}{l}\text { La cuencas hidrográficas no son aptas para el uso turístico, por diversos } \\
\text { temas como la contaminación de sus aguas. }\end{array}$ \\
\hline & Flora del lugar & $\begin{array}{l}\text { La flora es importante, tiene como recursos turísticos a los árboles na- } \\
\text { tivos como: el guabo (Inga insignis), mora quiteña (Rubus glaucus) y } \\
\text { ashpa chocho (Lupinus pubescens). }\end{array}$ \\
\hline & Fauna del lugar & $\begin{array}{l}\text { La fauna es diversa, pese a la urbanización agresiva de la parroquia, se } \\
\text { destacan especies de aves como: pájaro brujo (Pyrocephalus rubinus), } \\
\text { tórtola (Zenaida auriculata), golondrina (Hirundo rustica), mirlo (Tur- } \\
\text { dus fuscater) y quilicos (Falco sparverius). }\end{array}$ \\
\hline \multirow{6}{*}{$\begin{array}{c}\text { Componente } \\
\text { Hechos culturales }\end{array}$} & Iglesia vieja & $\begin{array}{l}\text { La primera construcción de esta iglesia fue en el año de } 1674 \text {. La tradición } \\
\text { oral de los tumbaqueños narra que la campana de la iglesia vieja fue fun- } \\
\text { dida con piezas de oro que entregaron las pobladoras de ese tiempo por su } \\
\text { gran devoción. Así mismo, cuenta esta tradición que los esposos de dichas } \\
\text { mujeres estuvieron presentes durante la fundición de esos metales. }\end{array}$ \\
\hline & La Cruz de Piedra & $\begin{array}{l}\text { Data de inicios del siglo XVI, fue la primera ubicada en el sector, y mues- } \\
\text { tra de eso es la inscripción que se encuentra en dicha cruz: "Esta cruz se } \\
\text { acabó el } 1 \text { de junio de } 1538 \text {, siendo cura vicario el Sr. Carlos Hecherría, } \\
\text { constituida con limosnas" (GAD Tumbaco, 2015). }\end{array}$ \\
\hline & La Cueva de Rafa & $\begin{array}{l}\text { Este restaurante se constituye en un atractivo cultural por cuanto ofrece la } \\
\text { oportunidad de comer a ciegas, en un entorno controlado que permite al } \\
\text { visitante experimentar el proceso como lo hace una persona no vidente. }\end{array}$ \\
\hline & $\begin{array}{l}\text { La ruta ciclística del } \\
\text { Chaquinán }\end{array}$ & $\begin{array}{l}\text { La ruta cubre un recorrido que inicia desde la parroquia de Cumbayá } \\
\text { hasta llegar a Puembo, atravesando un total de } 7 \text { paradas que surcan el } \\
\text { río Chiche y tres túneles de total oscuridad, que permiten las actividades } \\
\text { de ciclismo y caminatas. }\end{array}$ \\
\hline & $\begin{array}{l}\text { El balneario municipal de } \\
\text { Cununyacu }\end{array}$ & $\begin{array}{l}\text { El balneario es usado para el disfrute de los habitantes de Tumbaco, así como } \\
\text { para pobladores de la ciudad de Quito y de las demás parroquias rurales del } \\
\text { valle. Es una construcción icónica del valle de Tumbaco por su antigüedad. }\end{array}$ \\
\hline & La pesca San Isidro & $\begin{array}{l}\text { La especie que se cría para la actividad de la pesca es la trucha (Oncor- } \\
\text { hynchus mykiss), dentro del centro se prestan las facilidades e instru- } \\
\text { mentos necesarios para que los turistas realicen la actividad con todas } \\
\text { las seguridades del caso. }\end{array}$ \\
\hline $\begin{array}{l}\text { Componente } \\
\text { Gastronómico }\end{array}$ & Variedad gastronómica & 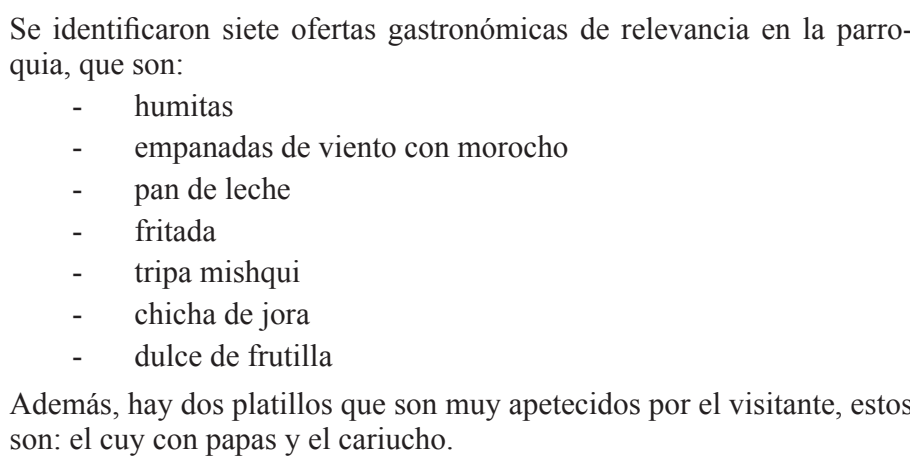 \\
\hline
\end{tabular}




\begin{tabular}{|c|c|c|}
\hline \multirow{4}{*}{$\begin{array}{l}\text { Componente } \\
\text { Festividades } \\
\text { y eventos }\end{array}$} & $\begin{array}{l}\text { La Inmaculada Concepción } \\
\text { de Tumbaco }\end{array}$ & $\begin{array}{l}\text { Esta es la principal fiesta de la parroquia de Tumbaco. Se celebra del } \\
29 \text { de noviembre hasta el } 12 \text { de diciembre de cada año. Los eventos que } \\
\text { se realizan en este periodo son son muy llamativos para los ciudadanos } \\
\text { de las cercanías. }\end{array}$ \\
\hline & Colla Raimy & $\begin{array}{l}\text { Tiene un gran potencial cultural. La celebración de la fiesta es en el mes } \\
\text { de agosto, donde se demuestra el acervo cultural que han conservado las } \\
\text { comunas de Leopoldo N. Chávez y la comuna Central. }\end{array}$ \\
\hline & San Pedro y San Pablo & $\begin{array}{l}\text { La fecha clave de esta celebración es el } 29 \text { de junio de cada año, destaca } \\
\text { por su alta representatividad cultural, destacándose los personajes que } \\
\text { visten sus mejores galas y cumplen los diferentes rituales que en dicha } \\
\text { fiesta se contemplan. Varios personajes propios de esta tradición salen } \\
\text { a las calles vestidos de gala. }\end{array}$ \\
\hline & La carrera del Chaquiñán & $\begin{array}{l}\text { Un evento importante que se realiza en el campo deportivo es esta carrera } \\
\text { de atletismo de } 5 \mathrm{~km} \text {, que lleva dos años de realización y atrae a depor- } \\
\text { tistas de todo el país. }\end{array}$ \\
\hline \multirow{5}{*}{$\begin{array}{l}\text { Componente } \\
\text { Actividades } \\
\text { recreacionales }\end{array}$} & Ciclismo & $\begin{array}{l}\text { Los paseos, como el del Chaquiñán, permiten que los turistas lleguen a } \\
\text { la parroquia por esta actividad y hagan uso de los diferentes servicios } \\
\text { turísticos. }\end{array}$ \\
\hline & Avistamiento de aves & $\begin{array}{l}\text { Las aves de la parroquia son admiradas desde varios lugares como el } \\
\text { mirador ubicado en el cerro Ilaló, los cuales por su cercanía son visitados } \\
\text { por varias personas. }\end{array}$ \\
\hline & Pesca deportiva & $\begin{array}{l}\text { Las truchas son la principal especie que se utiliza en esta actividad. Es } \\
\text { apetecida por los turistas nacionales y extranjeros. }\end{array}$ \\
\hline & Natación & $\begin{array}{l}\text { Los ciudadanos prefieren las aguas de origen fluvial por sus beneficios } \\
\text { naturales, en este caso, para la natación dan preferencia al balneario de } \\
\text { Cunuyacu. }\end{array}$ \\
\hline & Campeonatos de futbol & $\begin{array}{l}\text { Los campeonatos de fútbol son un gran atractivo, sobre todo en torneos } \\
\text { con parroquias y cantones periféricos. }\end{array}$ \\
\hline $\begin{array}{l}\text { Componente } \\
\text { Vías de acceso }\end{array}$ & Acceso terrestre & $\begin{array}{l}\text { La parroquia de Tumbaco posee diferentes vías de acceso terrestre, ya } \\
\text { que ésta se encuentra al costado de uno de los accesos al nuevo Aero- } \\
\text { puerto Internacional Mariscal Sucre en Tababela. }\end{array}$ \\
\hline \multirow{4}{*}{$\begin{array}{l}\text { Componente } \\
\text { Seguridad, } \\
\text { Salud, } \\
\text { Servicios Básicos }\end{array}$} & Seguridad & $\begin{array}{l}\text { La parroquia cuenta con apoyo interinstitucional de seguridad, tanto de } \\
\text { la Policía Nacional, Bomberos, Secretaría Nacional de Riesgos y Cruz } \\
\text { Roja, entidades que, tanto por su localización en el territorio como por su } \\
\text { cercanía a Quito, brindan seguridad al turista. }\end{array}$ \\
\hline & Servicios de Salud & $\begin{array}{l}\text { La parroquia cuenta con } 23 \text { establecimientos de atención médica para } \\
\text { el turista, entre ellos: dos centros de atención pública, una fundación y } \\
\text { veinte consultorios privados. }\end{array}$ \\
\hline & Servicios básicos & $\begin{array}{l}\text { El Municipio del Distrito Metropolitano de Quito brinda a la parroquia } \\
\text { casi el } 100 \% \text { de servicios básicos tanto de energía eléctrica, agua pota- } \\
\text { ble y alcantarillado, elementos indispensables para el funcionamiento de } \\
\text { servicios turísticos. }\end{array}$ \\
\hline & Otros servicios & $\begin{array}{l}\text { La parroquia cuenta con cobertura de servicios de telefonía fija y móvil, } \\
\text { así como el Internet vía banda ancha y fibra óptica. }\end{array}$ \\
\hline
\end{tabular}




\begin{tabular}{|c|c|c|}
\hline \multirow{4}{*}{$\begin{array}{l}\text { Componente } \\
\text { Servicios turísticos }\end{array}$} & Alojamiento & $\begin{array}{l}\text { Se cuenta con } 4 \text { establecimientos hoteleros y extrahoteleros dentro de la } \\
\text { parroquia. Aunque la capacidad de alojamiento es baja, su proximidad a } \\
\text { Quito, solventa esta necesidad de sus visitantes. }\end{array}$ \\
\hline & Alimentación & $\begin{array}{l}\text { Existen cerca de } 33 \text { establecimientos de alimentación y bebidas, entre los } \\
\text { que están cafeterías, heladerías y fuentes de soda, siendo este uno de los } \\
\text { servicios turísticos con mayor demanda (Cabanilla, 2011). }\end{array}$ \\
\hline & Transportación & $\begin{array}{l}\text { Debido al buen estado de las vías de acceso terrestre se encuentran dife- } \\
\text { rentes cooperativas de transporte público, cooperativas de camionetas y } \\
\text { transporte intraparroquial. }\end{array}$ \\
\hline & Otros servicios & $\begin{array}{l}\text { Aparte, se cuenta con una discoteca, un balneario y cuatro agencias de } \\
\text { viajes registradas en el Catastro Turístico Parroquial. }\end{array}$ \\
\hline \multirow{2}{*}{$\begin{array}{l}\text { Componente } \\
\text { Consumidor }\end{array}$} & Visitante nacional & $\begin{array}{l}\text { El turista nacional que visita la parroquia está en edades entre los } 18 \text { y } \\
45 \text { años. Gusta de actividades recreativas, gastronómicas, y asistir a sus } \\
\text { festividades. }\end{array}$ \\
\hline & Visitante internacional & $\begin{array}{l}\text { Gran cantidad de los turistas extranjeros que visitan la parroquia no se } \\
\text { quedan a dormir en el territorio, pero gustan de actividades turísticas, } \\
\text { como el ciclismo, el avistamiento de aves y la pesca deportiva. }\end{array}$ \\
\hline \multirow{2}{*}{$\begin{array}{l}\text { Componente } \\
\text { Promoción/ } \\
\text { comercialización }\end{array}$} & $\begin{array}{l}\text { Instituciones encargadas de la } \\
\text { promoción }\end{array}$ & $\begin{array}{l}\text { La Junta Parroquial se encarga de promocionar turísticamente sus re- } \\
\text { cursos, sin embargo, la capacidad es muy limitada. A esto se suma las } \\
\text { aisladas promociones del Municipio de Quito, que las realiza para las } 33 \\
\text { parroquias rurales. }\end{array}$ \\
\hline & Medios utilizados & $\begin{array}{l}\text { La parroquia se promociona vía Web, revistas y un periódico local. } \\
\text { La parroquia no cuenta con un infocentro o un mapa turístico de su te- } \\
\text { rritorio. }\end{array}$ \\
\hline \multirow{2}{*}{$\begin{array}{l}\text { Componente } \\
\text { Políticas } \\
\text { administrativas }\end{array}$} & Políticas nacionales & $\begin{array}{l}\text { Políticas nacionales que ayudan a la gestión turística de la parroquia } \\
\text { son el PLANDETUR 2020, el Plan Nacional para el Buen Vivir, la } \\
\text { Ley Orgánica de Turismo, entre otras, que no han sido ancladas a } \\
\text { nivel local y no han sido utilizadas como soporte para proyectos de } \\
\text { desarrollo en este sector. }\end{array}$ \\
\hline & Políticas locales & $\begin{array}{l}\text { La parroquia se rige a las ordenanzas del Municipio del DM de Quito, así } \\
\text { como a los reglamentos que emite la administración parroquial, sin em- } \\
\text { bargo, no hay ordenanzas locales sobre el funcionamiento del turismo. }\end{array}$ \\
\hline \multirow{4}{*}{$\begin{array}{l}\text { Componente } \\
\text { Instituciones } \\
\text { administrativas }\end{array}$} & Públicas & $\begin{array}{l}\text { Entre los entes administrativos que están inmiscuidos en el sector } \\
\text { turístico en la parroquia están: el Gobierno Provincial de Pichincha, } \\
\text { el Municipio de Quito y la Junta Parroquial, sin embargo, no han lo- } \\
\text { grado establecer un trabajo mancomunado. }\end{array}$ \\
\hline & Privada & $\begin{array}{l}\text { La empresa privada vinculada con el turismo es especialmente gastronó- } \\
\text { mica. Hay un abanico de otros sectores, especialmente comerciales, pero } \\
\text { no están ligados con el lugar. }\end{array}$ \\
\hline & Académico & $\begin{array}{l}\text { Se encuentran dos universidades, una de carácter público, la Universi- } \\
\text { dad Central, y otra privada, la Universidad de Especialidades Turísticas } \\
\text { que han realizado trabajos puntuales de vinculación sobre el área. }\end{array}$ \\
\hline & Comunitario & $\begin{array}{l}\text { Existen dos comunidades legalmente organizadas: la comuna Central } \\
\text { y la comuna Leopoldo N. Chávez que han mostrado interés por el de- } \\
\text { sarrollo del turismo, pero no han logrado establecer un plan conjunto, } \\
\text { ni individual. }\end{array}$ \\
\hline
\end{tabular}




\subsection{Expectativa de la población turística frente al posible desarrollo del turismo}

Para evaluar la expectativa del poblador local, en relación con el desarrollo de las actividades turísticas en la parroquia, fue necesario la aplicación de una encuesta realizada al azar a los habitantes de la parroquia de Tumbaco. Para la obtención de una in- formación fehaciente se obtuvo una muestra con un grado de confiabilidad del $95 \%$, margen de error de $+/-5 \%$ y una varianza del $50 \%$ sobre una población de 49.944 habitantes, según el último Censo Nacional de Población de 2010 (INEC, 2010). Se obtuvo una muestra de 377 encuestas que fueron aplicadas en zonas públicas (Cabanilla, 2011), y cuyos datos demográficos se resumen en la Tabla 2.

Tabla 2. Características demográficas de la muestra.

\begin{tabular}{|c|c|c|c|}
\hline \multirow{2}{*}{ Género } & $\begin{array}{c}\text { El 57\% corresponde al género masculinos y } \\
43 \% \text { al género femenino }\end{array}$ & Grupos de Edad & $15-21$ años $20 \%$ \\
& & & $22-35$ años $54 \%$ \\
& 36 o más $26 \%$ \\
\hline $\begin{array}{c}\text { Actividad } \\
\text { económica }\end{array}$ & $19 \%$ estudios, $80 \%$ trabajo dependiente, $1 \%$ quehaceres domésticos \\
\hline
\end{tabular}

Los principales resultados de este grupo demuestran que el 95\% considera que su localidad tiene potencialidad para el turismo nacional, mientras que el $65 \%$ manifiesta que también puede ofrecer lugares para el turismo receptivo, especialmente en la zona rural. Así también, de acuerdo con sus observaciones manifiestan que las cinco principales actividades que realizan los visitantes en su territorio son: caminatas en el sector de Ilaló (19\%), paseos en bicicleta (18\%), consumo de alimentos y bebidas (15\%), visitas culturales $(12 \%)$ y pesca deportiva $(9 \%)$.

Los lugares más visitados, según la opinión local, son: el cerro Ilaló, el cañón del río Chiche, el complejo turístico el Gran Marcelino, las piscinas de Cunuyacu y el ciclo paseo del Chaquiñán. Los habitantes consideraron, por unanimidad, que con un plan de desarrollo turístico, la parroquia se podría convertir en un destino de importancia para visitantes nacionales e internacionales.

Aunque hubo unanimidad en la potencialidad turística parroquial, el $80 \%$ lo perciben como un sector que beneficiaría a diversos sectores produc- tivos locales, mientras que un $20 \%$ manifiesta que tan solo crearía mayor acumulación de capital en ciertos grupos de la población local. Finalmente, en una comparación con parroquias vecinas, manifestaron que la parroquia está en un término medio, detrás de Cumbayá y sobre Pifo o Puembo.

Con los resultados obtenidos mediante el levantamiento de información y para un mejor análisis se realizó una matriz FODA, que se describe en el apartado 3.3.

\subsection{Evaluación FODA de los elementos estudiados}

Con todos los elementos compilados, en el trabajo de campo y en las encuestas a los pobladores locales, se procedió a elaborar un diagnóstico de fortalezas, oportunidades, debilidades y amenazas del turismo en Tumbaco (Tabla 3). De este trabajo se procedió a elaborar un mapa de objetivos estratégicos "ofensivos y defensivos" de cada uno de los componentes analizados. 
Tabla 3. FODA del sistema turístico de la parroquia de Tumbaco.

\begin{tabular}{|c|c|c|c|c|}
\hline COMPONENTES: & FORTALEZAS & OPORTUNIDADES & DEBILIDADES & AMENAZAS \\
\hline $\begin{array}{c}\text { Componente } \\
\text { natural }\end{array}$ & $\begin{array}{l}\text { F1 Está ubicado en } \\
\text { las faldas del cerro } \\
\text { Ilaló, alberga flora } \\
\text { y fauna de interés } \\
\text { para la observación } \\
\text { e interpretación. }\end{array}$ & $\begin{array}{l}\text { O1 Utilizar los proyectos } \\
\text { que se generan en beneficio } \\
\text { del ambiente y la ecología } \\
\text { por parte del municipio, go- } \\
\text { bierno provincial y organis- } \\
\text { mos no gubernamentales. }\end{array}$ & $\begin{array}{l}\text { D1 Las cuencas y micro- } \\
\text { cuencas se encuentran } \\
\text { contaminadas, inútiles } \\
\text { para el uso turístico y } \\
\text { factor de riesgo para la } \\
\text { contaminación. }\end{array}$ & $\begin{array}{l}\text { A1 Incendios fores- } \\
\text { tales provocados, ca- } \\
\text { tástrofes naturales y } \\
\text { vulnerabilidad frente } \\
\text { a riesgos climáticos. }\end{array}$ \\
\hline $\begin{array}{c}\text { Componente } \\
\text { hechos culturales }\end{array}$ & $\begin{array}{l}\text { F1 Cuenta con } \\
\text { atractivos cultura- } \\
\text { les diversos y de } \\
\text { gran importancia } \\
\text { histórica. }\end{array}$ & $\begin{array}{l}\text { O1 Enmarcarse en proyec- } \\
\text { tos de revitalización cultu- } \\
\text { ral auspiciados por diver- } \\
\text { sas instituciones. }\end{array}$ & $\begin{array}{l}\text { D1 Deficiente turistifica- } \\
\text { ción de los recursos cul- } \\
\text { turales de la parroquia. }\end{array}$ & $\begin{array}{l}\text { A1 Invisibilidad de } \\
\text { lo cultural dentro del } \\
\text { territorio. }\end{array}$ \\
\hline $\begin{array}{l}\text { Componente } \\
\text { gastronómico }\end{array}$ & $\begin{array}{l}\text { F1 Elementos cu- } \\
\text { linarios de gran } \\
\text { relevancia y muy } \\
\text { atractivos para los } \\
\text { visitantes. }\end{array}$ & $\begin{array}{l}\text { O1 Mayor movilización } \\
\text { de visitantes por el tema } \\
\text { gastronómico. }\end{array}$ & $\begin{array}{l}\text { D1 No hay restaurantes } \\
\text { especializados en comi- } \\
\text { da tradicional del lugar } \\
\text { para la oferta turística. }\end{array}$ & $\begin{array}{l}\text { A1 Lugares de proxi- } \\
\text { midad pueden ab- } \\
\text { sorber la oferta gas- } \\
\text { tronómica de este } \\
\text { territorio e inclusive } \\
\text { apropiarse de esta. }\end{array}$ \\
\hline $\begin{array}{l}\text { Componente } \\
\text { festividades y } \\
\text { eventos }\end{array}$ & $\begin{array}{l}\text { F1 Festividades } \\
\text { tradicionales con } \\
\text { gran potencial tu- } \\
\text { rístico, abiertas a } \\
\text { los visitantes, den- } \\
\text { tro de los barrios y } \\
\text { las comunas de la } \\
\text { parroquia. }\end{array}$ & $\begin{array}{l}\text { O1 Existe mayor movili- } \\
\text { dad por concurrir a even- } \\
\text { tos y festividades en el } \\
\text { área rural. }\end{array}$ & $\begin{array}{l}\text { D1 Inexistencia de es- } \\
\text { pacios adecuados para } \\
\text { la socialización de estos } \\
\text { eventos o festividades. }\end{array}$ & $\begin{array}{l}\text { A1 Otras comuni- } \\
\text { dades tienen fiestas } \\
\text { y eventos similares } \\
\text { con mejor posiciona- } \\
\text { miento y mayor pro- } \\
\text { moción. }\end{array}$ \\
\hline $\begin{array}{l}\text { Componente } \\
\text { actividades } \\
\text { recreacionales }\end{array}$ & $\begin{array}{l}\text { F1 Oferta diversifi- } \\
\text { cada de actividades } \\
\text { recreacionales. }\end{array}$ & $\begin{array}{l}\text { O1 Puesta en valor de los } \\
\text { lugares aptos para activi- } \\
\text { dades recreacionales. }\end{array}$ & $\begin{array}{l}\text { D1 Deficiencia en per- } \\
\text { sonal capacitado para } \\
\text { la gestión, implementa- } \\
\text { ción y difusión de estas } \\
\text { actividades. }\end{array}$ & $\begin{array}{l}\text { A1 Parroquias aleda- } \\
\text { ñas con similar oferta. }\end{array}$ \\
\hline $\begin{array}{c}\text { Componente } \\
\text { vías de acceso }\end{array}$ & $\begin{array}{l}\text { F1 Red vial en ex- } \\
\text { celente estado para } \\
\text { el acceso hacia la } \\
\text { parroquia por la } \\
\text { vía Interoceánica, } \\
\text { así como por la } \\
\text { nueva Ruta Viva } \\
\text { que conduce hacia } \\
\text { el aeropuerto Ma- } \\
\text { riscal Sucre. }\end{array}$ & $\begin{array}{l}\text { O1 Paso estratégico para } \\
\text { movilidades entre el ae- } \\
\text { ropuerto internacional, el } \\
\text { Santuario de El Quinche, } \\
\text { Papallacta, entre otros } \\
\text { destinos turísticos. }\end{array}$ & $\begin{array}{l}\text { D1 Sectores alejados de } \\
\text { la vía principal, tienen } \\
\text { vías de menor calidad } \\
\text { y, en algunos casos, de } \\
\text { difícil acceso vehicular. }\end{array}$ & $\begin{array}{l}\text { A1 Tráfico intenso de- } \\
\text { bido al continuo paso } \\
\text { de vehículos, tanto li- } \\
\text { vianos como pesados, } \\
\text { que viajan a diferentes } \\
\text { lugares del país. }\end{array}$ \\
\hline $\begin{array}{l}\text { Componente } \\
\text { seguridad, } \\
\text { salud y } \\
\text { servicios básicos. }\end{array}$ & $\begin{array}{l}\text { F1 Buena cobertu- } \\
\text { ra de servicios bá- } \\
\text { sicos e institucio- } \\
\text { nes que garantizan } \\
\text { la seguridad del } \\
\text { visitante. }\end{array}$ & $\begin{array}{l}\text { O1 Para casos especiales } \\
\text { proximidad de servicios } \\
\text { especializados en parro- } \\
\text { quias aledañas. }\end{array}$ & $\begin{array}{l}\text { D1 Cerca del } 2 \% \text { de la } \\
\text { población se encuentra } \\
\text { exenta de la cobertura } \\
\text { de servicios como al- } \\
\text { cantarillado y recolec- } \\
\text { ción de basura. }\end{array}$ & $\begin{array}{l}\text { A1 Epidemias e inse- } \\
\text { guridad causada por } \\
\text { riesgos naturales. }\end{array}$ \\
\hline $\begin{array}{c}\text { Componente } \\
\text { servicios turísticos }\end{array}$ & $\begin{array}{l}\text { F1 Existencia de } \\
\text { servicios de alimen- } \\
\text { tación, alojamiento } \\
\text { y transporte. }\end{array}$ & $\begin{array}{l}\text { O1 Fortalecimiento de } \\
\text { servicios existentes y po- } \\
\text { lítica de auspicio a nuevas } \\
\text { inversión-es. }\end{array}$ & $\begin{array}{l}\text { D1 No hay control sobre } \\
\text { los servicios turísticos, } \\
\text { como por ejemplo, el de } \\
\text { alojamiento que se ofer- } \\
\text { ta para uso por horas. }\end{array}$ & $\begin{array}{l}\text { A1 Parroquias aleda- } \\
\text { ñas que desarrollan } \\
\text { proyectos turísticos } \\
\text { de calidad. }\end{array}$ \\
\hline
\end{tabular}




\begin{tabular}{|c|c|c|c|c|}
\hline $\begin{array}{l}\text { Componente } \\
\text { consumidor }\end{array}$ & $\begin{array}{l}\text { F1 Afluencia de } \\
\text { recreacionistas, tu- } \\
\text { ristas nacionales e } \\
\text { internacionales. }\end{array}$ & $\begin{array}{l}\text { O1 Sistema estadístico de } \\
\text { seguimiento y control de } \\
\text { satisfacción del visitante. }\end{array}$ & $\begin{array}{l}\text { D1 Desconocimiento de } \\
\text { las motivaciones de los } \\
\text { turistas que visitan la pa- } \\
\text { rroquia con regularidad. }\end{array}$ & $\begin{array}{l}\text { A1 Competencia de } \\
\text { productos similares en } \\
\text { parroquias aledañas. }\end{array}$ \\
\hline $\begin{array}{l}\text { Componente } \\
\text { promoción } \\
\text { comercialización }\end{array}$ & $\begin{array}{l}\text { F1 La parroquia } \\
\text { cuenta con una re- } \\
\text { vista periódica tri- } \\
\text { mestral en la cual } \\
\text { se difunde la in- } \\
\text { formación de dife- } \\
\text { rentes temas, entre } \\
\text { ellos el turismo. }\end{array}$ & $\begin{array}{l}\text { O1 Utilizar redes sociales } \\
\text { y medios de comunicación } \\
\text { alternativos. }\end{array}$ & $\begin{array}{l}\text { D1 Información básica } \\
\text { en los portales Web e } \\
\text { impresos. No existe una } \\
\text { investigación turística } \\
\text { eficiente. }\end{array}$ & $\begin{array}{l}\text { A1 La información } \\
\text { turística de otras pa- } \\
\text { rroquias podría invisi- } \\
\text { bilizar a Tumbaco. }\end{array}$ \\
\hline $\begin{array}{c}\text { Componente } \\
\text { políticas } \\
\text { administrativas }\end{array}$ & $\begin{array}{l}\text { F1 Política nacional } \\
\text { y cantonal de desa- } \\
\text { rrollo al turismo. }\end{array}$ & $\begin{array}{l}\text { O1 La legislación actual } \\
\text { motiva a la inversión ex- } \\
\text { tranjera de proyectos en } \\
\text { sectores estratégicos como } \\
\text { el turismo. }\end{array}$ & $\begin{array}{l}\text { D1 No existen políticas } \\
\text { propias de la parroquia } \\
\text { para mejorar o incenti- } \\
\text { var el desarrollo de las } \\
\text { actividades turísticas. }\end{array}$ & $\begin{array}{l}\text { A1 La legislación } \\
\text { ecuatoriana con cons- } \\
\text { tantes cambios e ines- } \\
\text { tabilidad. }\end{array}$ \\
\hline $\begin{array}{c}\text { Componente } \\
\text { instituciones } \\
\text { administrativas }\end{array}$ & $\begin{array}{l}\text { F1 Apoyo por parte } \\
\text { de entidades guber- } \\
\text { namentales, institu- } \\
\text { ciones educativas y } \\
\text { empresa privada a } \\
\text { ciertas actividades } \\
\text { turísticas. }\end{array}$ & $\begin{array}{l}\text { O1 Las autoridades del Es- } \\
\text { tado por medio del cambio } \\
\text { de matriz estratégica están } \\
\text { dispuestos a apoyar activi- } \\
\text { dades sustentables como el } \\
\text { turismo. }\end{array}$ & $\begin{array}{l}\text { D1 Insuficiente apoyo } \\
\text { para el desarrollo inte- } \\
\text { gral en materia turística } \\
\text { de la parroquia. }\end{array}$ & $\begin{array}{l}\text { A1 El municipio de } \\
\text { Quito prioriza otras } \\
\text { parroquias. }\end{array}$ \\
\hline
\end{tabular}

Los objetivos estratégicos fueron la base para exponer los parámetros a considerar en una planifi- cación turística de la parroquia, que se presentan en la Tabla 4.

Tabla 4. Parámetros de una estrategia turística de la parroquia de Tumbaco.

\begin{tabular}{|l|l|}
\hline \multirow{2}{*}{ En lo natural: } & $\begin{array}{l}\text { Recuperar y mantener la flora y fauna insigne del territorio, en lugares como el } \\
\text { cerro Ilaló y sus alrededores, como punto estratégico para ecoturismo. }\end{array}$ \\
\cline { 2 - 3 } & $\begin{array}{l}\text { Ejecutar campañas de concientización sobre la convivencia armónica } \\
\text { con el medio ambiente. }\end{array}$ \\
\hline \multirow{2}{*}{ Sobre los hechos culturales: } & $\begin{array}{l}\text { Asignar valor turístico a los recursos culturales insignes de la parroquia. } \\
\text { Promocionar los recursos turísticos culturales del territorio, para que } \\
\text { sean incluidos en circuitos organizados de visita. }\end{array}$ \\
\hline \multirow{2}{*}{ En lo gastronómico: } & $\begin{array}{l}\text { Incentivar, mediante beneficios catastrales, la adopción de un menú que } \\
\text { contenga los platos representativos del lugar. }\end{array}$ \\
\cline { 2 - 3 } & $\begin{array}{l}\text { Promover encuentros y ferias gastronómicas, auspiciados por los } \\
\text { servicios de alimentos y bebidas de la parroquia, para promocionar la } \\
\text { oferta local. }\end{array}$ \\
\hline
\end{tabular}




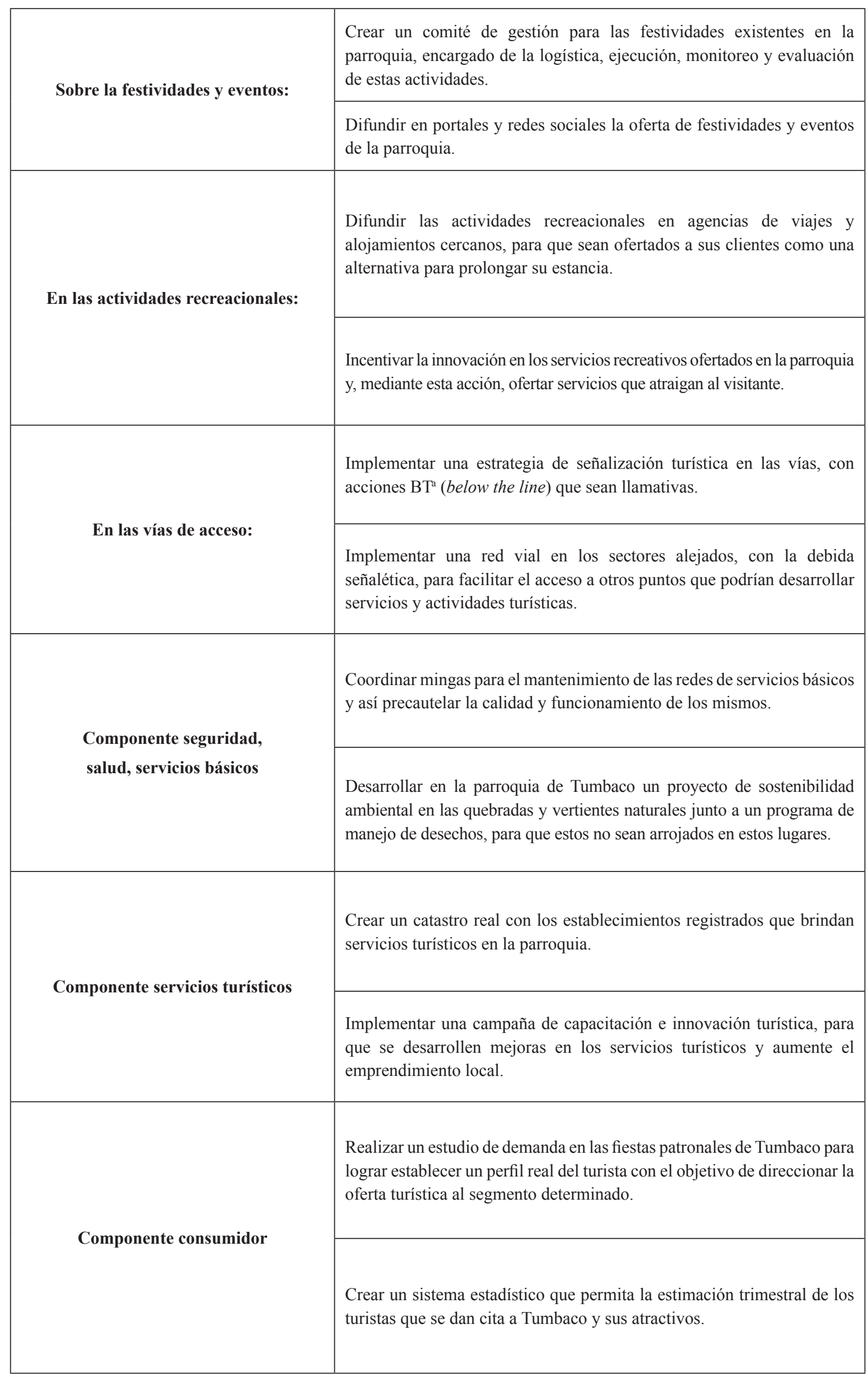




\section{Referencias}

Cabanilla, E. (2013). Turismo comunitario: del diagnóstico al plan de negocios. Bahía Blanca-Argentina: Licencia Creative commons atribución.

Cabanilla, E. (2011). Metodología para elaborar un estudio por encuestas de la satisfacción del turista: aplicación Quito, Ecuador. RICIT: Revista Turismo, Desarrollo y Buen Vivir (2), 8-26.

Cabanilla, E. (2011). Tendencias de consumo de alimentos y bebidas en Cumbayá-Tumbaco. RICIT: Revista Turismo, Desarrollo y Buen Vivir (2), 53-72.

Empresa Pública Metropolitana de Movilidad y Obras Públicas. (2016). Mapa Ruta Viva. Recuperado de: www.epmmop.gob.ec

Gobierno Autónomo Descentralizado de Tumbaco. (2012). Plan de Desarrollo y Ordenamiento Territorial de la Parroquia de Tumbaco 2012 - 2025. Quito.

Gobierno Autónomo Descentralizado de Tumbaco. (2015). Iglesias y capillas. Quito. Recuperado de: http://www.tumbaco.gob.ec/web/turismo/ lugares-que-visitar/iglesias-y-capillas.
Gobierno Autónomo Descentralizado de Tumbaco. (2015). Página oficial de Tumbaco. Quito: Autor. Recuperado de: http://www.tumbaco. gob.ec/web/turismo/lugares-que-visitar/balneario-municipal-cununyacu

Gobierno Autónomo Descentralizado de Tumbaco. (2015). Plan de Desarrollo y Ordenamiento Territorial. Quito.

Molina, E., \& Cabanilla, E. (2015). Posicionamiento de destinos turísticos: propuesta de modelo de gestión territorial. XII jornadas de investigación acción en turismo. Universidad nacional de Comahue.

Portón del Valle. (2014). Ruta Collas - nuevo aeropuerto. Quito: Recuperado de: http://www.portondelvalle.com/ruta-collas-nuevo-aeropuerto/

Wikimedia. (2015). Mapa parroquia de Tumbaco. Quito: Recuperado de: https://commons. wikimedia.org/wiki/File:Mapa_Parroquia_ Tumbaco_(Quito).svg 